Çukurova Üniversitesi Mühendislik Mimarlık Fakültesi Dergisi, 29(1), 109-125 ss., Haziran 2014

Çukurova University Journal of the Faculty of Engineering and Architecture, 29(1), pp.109-125, June 2014

\title{
Sülfürlü Mineraller İçeren Maden Yataklarında İşletme Sırasında ve Sonrasında Asit Kaya (Maden) Drenajlarının Oluşup Oluşmayacağına Yönelik Kestirimler: Akdağ, Karıncadağ ve Bolkardağ Örneği
}

\section{Bölüm: Genel Jeolojik Durum, Parajenezdeki Minerallerin Mineralojisi}

\author{
Mesut ANIL $^{1 *}$, Ali Can ÖZDEMIR ${ }^{1}$, Zehra ALTINÇELEP ${ }^{1}$ ve Emine DEMIREL ${ }^{1}$ \\ ${ }^{1}$ Ç.Ü., Mühendislik-Mimarlık Fakültesi, Maden Mühendisliği Bölümü, Adana
}

\section{Özet}

Parajenezlerinde sülfürlü mineraller içeren madenlerin gerek işletilmeleri sırasında ve gerekse işletme sonrası başta akifer kaynakları olmak üzere çevrede oluşturacakları asit kaya/maden drenajı oluşup oluşmayacağının önceden kestirilmesi önemlidir. Türkiye'de son 20 yıldır önem kazanan bu konularda henüz bir geleneğin oluşturulduğu söylenemez. Ancak özellikle düşük tenörlü altın madenleriyle gündeme gelen çok geniş alanlarda sürdürülen açı işletmeler ve büyük hacimli topografik değişimler çevresel kirlenmeler konusunda dikkat çekmiş ve asit kaya/maden drenajlarının sorgulanmasını gerektirmiştir. Bu çalışmada varlığı Roma Döneminden beri bilinen Bolkardağ, Karıncadağ ve Akdağ polimetalik parajenezlerinde yer alan başta pirit olmak üzere sülfürlü minerallerin oluşturacağ 1 asidite ile bunları nötürlemede en etkin formasyonlar olan karbonatlı yankayaçlar dikkate alınarak kestirimde bulunulmuştur. Birinci bölümde öngörülerin (kestirimin) yapılabilmesi için cevherleşmelerin görüldüğü bölgenin genel jeolojisi özetlenmiş, önceki çalışmalar ve bu dönemde alınan numunelerin parajenezindeki tüm minerallerin mineralojik incelemesi hem cevher mikroskopisi ve hem de kimyasal içerikleri XRF yöntemiyle kontrol edilmiş ve XRD difraktometreleri çekilerek faz analizleri yapılmıştır. İkinci bölümde ise derlenen verilere göre asit/baz hesaplamaları yapılarak drenajın oluşup oluşmayacağına karar verilecektir.

Anahtar Kelime: Genel jeoloji, Sülfürlü mineraller, Mineraloji, Asit kaya/Maden drenaj1, Karıncadağ- Bolkardağ

\section{Predictions Related to Whether Acide Mine Drainages will Occur or not in Mine Deposits Containing Sulphurous Minerals During and after Operating: Examples of Akdağ, Karıncadă̆ and Bolkardağ}

\section{Chapter 1: General Geological Situation, Mineralogy of the Mineral Paragenesis}

\begin{abstract}
It is important that the prediction of whether acide mine drainage will be occur or not at the mines containing sulphurous minerals in their paragenesis not only during the processing but also after the exploitation. It cannot be said to being created a custom about these issues coming into prominence in the

\footnotetext{
* Yazışmaların yapılacağı yazar: Mesut ANIL, Ç.Ü. Mühendislik Mimarlık Fakültesi, Maden Mühendisliği Bölümü, Adana.manil@cu.edu.tr
} 
Sülfürlü Mineraller İçeren Maden Yataklarında Isşletme Sırasında ve Sonrasında Asit Kaya (Maden) Drenajlarının Oluşup Oluşmayacağına Yönelik Kestirimler: Akdă̆, Karıncadă̆ ve Bolkardă̆ Örneği, 1. Bölüm

last 20 years. But, open pit mines exploited in too large area due to low grade gold mines and topographic changes at spacious volumes attracted the attention about environmental contamination and necessitated to being investigated acid mine drainages. In this study, it was foretold by considering acidity which will be created by sulphurous minerals such as pyrite located on Bolkardağ, Karıncadağ and Akdağ polymetallic paragenesises known since Roman ages and carbonated wall rock formations which are the best affective formation for neutralising this acidity. In the first chapter, general geology of the area was summarized and mineralogical analysises of all of the minerals in the paragenesis were revealed by applying XRF and XRD methods addition to ore microscopy method. In the second chapter, whether drainage will be occur or not is going to be decided by calculating acid/base equilibrium according to the compiled data.

Key Words: General geology, Mineralogy, Sulphide minerals, Acid rock/mine of the drainage, Karıncadağ-Bolkardağ,

\section{GíRiş}

$\mathrm{Bu}$ makale sayfa sınırlaması sebebiyle zorunlu olarak iki bölüm halinde yayına hazırlanmıştır.

İlksel konumları itibariyle derinde oluşan ve buradayken doğal dengede bulunan sülfürlü mineralizasyonlar, jeolojik zaman içindeki tektonik aşınımlara bağlı olarak ekonomik seviyelere kadar aşınır ve hatta yüzeyde mostra verebilirler. Burada meteorik etkilere açık hale gelen bu cevherleşmeler ikincil alterasyona maruz kalarak erime-iyonlaşma- hidroliz ve oksitlenme olayları bir dizi dönüşüm ürünlerini oluşturabilirler.

Yüzeysel suların hava ile etkin olduğu zonlarda (yıkanma, oksitlenme, demir şapka, üst sülfit zonları gibi) silikat minerallerinin duraylılı̆̆ esas olarak çözeltinin pH'ına bağlıdır. Piritin yüzeysel sularla yıkanması (oksitlenmesi) sonucunda oluşan sülfürik asit, asit kaya/maden drenajına (AKD/AMD) sebep olur. Bu dönüşümler sırasında feldspat ve mafik mineraller (biyotit, piroksen, amfibol) hidroliz hızının artmasına sebep olurlar ve silikatların bozulması tetiklenir. $\mathrm{Bu}$ dönüşümlerde en yaygın ikincil mineraller: Kaolinit-illit-kuvars ve limonittir. Plajiyoklaz ve K-Feldspat, illit+kaolinit+serüzit'e dönüşür. Kimyasal bozuşma yani asit kaya/maden drenajı (AKD/AMD), yeraltı su tablasında veya hemen altında biter. Çünkü kayaçtaki kırık, çatlak ve boşluklarının su ile dolu olduğu yerlere $\mathrm{O}_{2}$ ve $\mathrm{CO}_{2}$ Kolayca ulaşamaz. Kimyasal bozuşmayı
(AKD/AMD) denetleyen diğer parametreler; minerallerin birleşimi, kayaçların dokusu, geçirgenliği, bölgedeki iklim koşulları, drenaj ağları, zaman, yüzeylenme süresi, yapısal konum ve yerel erozyonun taban düzeyidir [1].

Asit maden drenajının çeşitli yollarla su kaynaklarına karışması ve drenaj suyu içindeki ağır ve bazen de toksik (zehirleyici) metal konsantrasyonları suların kalitesini olumsuz etkileyebilir. Etkilenen bu suların kendi debileri, içerdikleri metal konsantrasyonları bölgedeki akarsuların bolluğu, klimatolojik değerler seyreltilmeyi sağlayacaklarından dolayı kirlenme derecesinde oldukça etkilidirler. Her maden sahasının kendine has asit drenajı üretme potansiyeli ve oluşan bu asiditeyi nötürleştirecek ya da azaltacak karşı koyma potansiyeli bulunmaktadır. $\mathrm{Bu}$ sebeple genel prensipleri aynı sayılan fakat uygulamada farklılıklar gösteren sülfürlü mineral içeren maden sahalarının mineralojik ve kimyasal özellikleri ayrıntılarıyla incelenerek yankayaç ve gang minerallerinin bileşimleri de dikkate alınarak pasif ve aktif yöntemler hem işletme öncesi kestirimler yapılarak, hem de işletme sırasında önlemler alarak asit drenajlarına karşı koyulmaktadır. Maden ömrünü tamamladıktan sonra da gerekli tedbirler alınarak artık yığınları ve derin çukurlar ve basamaklar oluşan işletme sahasının asit üretmemesi için önlemler alınarak kontrol kuyularından takip işlemleri tavizsiz yürütülmelidir [2]. Kimyasal bozuşma, Na-CaMg'un hızla yıkanması, $K$ ve Si'in yavaş yıkanması biçimindedir. Kimyasal bozuşma kaba 
bir dengeye ulasstıktan sonra ortamda limonit (çoğunlukla götit), kuvars ve kaolinit kalır. Silikat mineralleri hidroliz yoluyla çözüldüklerinden bozuşmaları için oksijene ihtiyaçları kalmaz [1].

Çevre sorunlarını doğuran sebeplerin üzeri çizilemeyeceğine göre bir taraftan üretim-tüketim ilişkisi sürdürülürken çevrenin daha da bozularak yaşanamaz hale gelmemesi için çözüm çabalarının sabırla sürdürülmesi önemli görüldüğünden gerek Birleşmiş Milletler Çevre Örgütü, gerek ulusal devletlerin kendi kuruluşları ve gerekse engellenemeyecek derecede büyüyen çevreci sivil toplum örgütleri koruma tedbirlerini yakından denetlemektedirler. Diğer yatırımlarda olduğu gibi sanayileşmenin olmazsa olmaz sektörü konumundaki madencilik alanında 20. yüzyıla kadar çevre üzerindeki muhtemel etkileri hesaba katılmadan ekonomik, siyasal ve askeri hedeflere paralel maden üretim politikaları yürütülmüştür. Diğer sanayi kollarında olduğu gibi maden işletmeleri ömürlerini doldurup sahalar terk edilirken önceki faaliyetler sırasında oluşan kirlilik, doğanın tahribatı ve sonraki yıllarda oluşması muhtemel tehditlere yönelik tedbirler alınmadan son noktanın konulması mümkün olabilmiştir. $\mathrm{Bu}$ zaman süresince olumsuzluklar yaşanmadığı sürece idari ve adli yaptırımlar da hayata geçirilmemiştir. İşletilmiş maden sahalarının olduğu gibi bırakılmasından bir süre sonra atmosferik yağışlar asidik drenajların oluşmasına sebep olmuş ve yavaş yavaş hem yeraltı su kaynakları ve hem de yüzeydeki toprağın ağır metaller (bazıları toksik özellikte olabilir) yönünden kirletilmeye başlamıştır. 1950'lere kadar pek çoğu küçük boyutta ve yeryüzüne yakın konumda olan açık işletmeler daha sonra devasa kazı makinalarının keşfi ve yüksek tenörlü madenlerin azalmasıyla daha düşük tenörlerde ama daha derinlerde yataklanmış madenlerin işletilmeye başlanmasıyla çok büyük boyutlu çukurların oluşmasını doğurmuştur. Yaşanan bir dizi olumsuzluklar üzerine çevre bilincinin de yaygınlaşması madencilerin faaliyetleri mercek altına alınarak siyasi iradelerce pek çok yaptırım uygulanmaya konulmuştur. İşte bu yaptırımların en yenilerinden olan asit-kaya veya asit-maden oluşup oluşmayacağı başta sülfürlü madenler olmak üzere birçok maden işletme ruhsatı için hazırlanacak ÇED raporlarında ayrı başlık altında istenmeye başlanmıştır. Herhangi bir madenin asit drenajı oluşturup oluşturmayacağı kararı verilmeden cevher minerallerinin mineralojik ve kimyasal özelliklerinin ayrıntılarıyla bilinmesi olmazsa olmaz şarttır. Bu sebeple asit üretme potansiyeli ve nötürleştirme potansiyelleri hesaplanmadan önce ruhsat sahasındaki kompleks cevherleşmesinin mineralojik ve jeokimyasal açıdan değerlendirilmesi önceki çalışmalar ve bu incelemeler sırasında alınan numuneler üzerinde çeşitli inceleme sonuçlarından yararlanılarak değerlendirilmiştir. $\mathrm{Bu}$ çalışmada yakın çevremizde bulunan Akdağ, Karıncadağ ve Bolkardağ çoğu karbonatlı platformlarda yataklanmış ve parajenezinde sülfürlü mineraller içeren maden sahalarında işletme ve işletme sonucunda asit kaya/maden drenajının oluşma ihtimalleri üzerinde durulmuş ve bu sorunun cevaplandırılması için gerekli olan mineralojik, petrografik ve kimyasal analizlerle bazı statik ve dinamik testlerin uygulamalarına yer verilmiştir.

\section{INCELEME ALANININ KISA GENEL JEOLOJISİ VE CEVHERLEŞMELERIN MINERALOJIK VE KIMYASAL ÖZELLIKKLERİ}

Adana İli, Pozantı İlçesi dahilinde bulunan çok sayıdaki maden sahasında yapılan ilk çalışmalarda kompleks cevher (kurşun, çinko, bakır, altın ve gümüş gibi polimetalik cevherleşmeler) belirlenmiştir. Romalılar döneminde de bu bölgedeki cevherleşmeler üzerinde yarma, kuyu ve galeri gibi çok derine inemeyen aramaların yapıldığı ve Karıncadağ'ın güneyinde kalan Akdağ karbonatlı kayaçlar içinde $\mathrm{Pb}-\mathrm{Zn}-\mathrm{Cu}$ damarlarının içinde yine Roma döneminden kalan eski çalışmaların varlığı bilinmektedir [3-5]. Cumhuriyet döneminde de bu bölgede cevher arama ve üretim gayretleri gösterilmiş ise de halen bölgede çalışmaları sürdüren Koza Altın İşletmeleri A.Ş. ve Gümüştaş Altın İşletmeleri'nin faaliyetleri uzunca bir süredir varlığ bölgedeki maden varlıklarının önemini artırmıştır. Üniversitelerdeki akademik çalışmaların 
Sülfürlü Mineraller İçeren Maden Yataklarında Isşletme Sırasında ve Sonrasında Asit Kaya (Maden) Drenajlarının Oluşup Oluşmayacağına Yönelik Kestirimler: Akdă̆, Karıncadă̆ ve Bolkardă̆ Örneği, 1. Bölüm

Bolkardă̆, Akdağ ve Karıncadağ'’ da içine alan ve Ulukışla'yı da kapsayan geniş bölgede başta $\mathrm{Pb}-\mathrm{Zn}-\mathrm{Cu}$ olmak üzere pirit, kalkopirit, sfalerit, galenit gibi birincil sülfür mineralleriyle bunların ikincil mineralleri limonit, smitsonit, serüzit, anglezit, malakit, azurit ve götit cevherleşmelerine sıkça rastlanılmış ayrıca kasiterit (kalay), gümüş, altın, molibden ile ofiyolitik zonların kontaklarında $\mathrm{Cr}$, $\mathrm{Ni}$ ve $\mathrm{Co}$ ile bazı demir cevherleşmeleri belirlenmiştir.

Önceki yıllarda 5-6 gr/ton'un altındaki $\mathrm{Au}$ tenörlerine rağbet yokken günümüzde altın fiyatlarındaki artışlar 1,5 gr/ton tenörün bile değerlendirilmeye alınabileceğini göstermektedir. $\mathrm{Bu}$ sebeple sahada yapılan çalışmalarda belirlenen cevherin üretimi yapılması ve pazarlanması planlanarak özel bir şirket tarafindan işletme projesi hazırlanmış ve Maden İşleri Genel Müdürlüğü (MİGEM)'ne sunulmuştur. Şirket elemanlarının sahada gerçekleştirdikleri çalışmalarda değişik yerlerinde bakır, kurşun, çinko cevherleşmesi belirlenmiştir. Arama çalışmalarının genişletilmesi ile görünür alan dışındaki alanlarda cevherleşme belirlenmesi durumunda bu alanlarda işletmeye geçilecektir. Sahada demir cevherleşmesi de belirlenmiş olup, potansiyeli ve kullanım durumunun belirlenmesi amacıyla çalışmalar devam etmektedir. İşletme projesinde ruhsat sahasında şirket elemanlarınca gerçekleştirilen prospeksiyon, jeolojik etüd, numune alımı ve analiz çalışmalarından sonra değişik alanlarda cevherleşme toplam $700 \mathrm{~m}$ uzunlukta ve ortalama $2 \mathrm{~m}$ kalınlığında olup cevher derinliğinin $30 \mathrm{~m}$, cevher yoğunluğunun 3,5 ton $/ \mathrm{m}^{3}$ olarak alındığında, işletme izin sahasında toplam 147.000 ton kompleks cevher varlığı belirlenmiştir. İşletme projesinde görünür rezerv alanı dışında da kompleks cevherleşmesi izlendiği belirtilmiş ve ruhsat sahasının çeşitli yerlerinde 70.000 ton civarında muhtemel cevher rezervi olabileceği tahmin edilmiştir. Ayrıca, görünür ve muhtemel rezerv alanı altındaki bölüm mümkün rezerv alanı olarak kabul edilmektedir. $\mathrm{Bu}$ sahaların ÇED uygunluk belgesi alındığı ve işletmeye geçmek için öteki faaliyetlerin sürdürüldüğü bilinmektedir. Ecemiş fay kuşağının batı bloğunda yer alan Bolkar mermer ve şistleri çalışma alanı içerisinde Karıncadağ ve güney kesimlerinde yüzeylenmektedir. Birim mermer, dolomitli mermer, dolomit ve bunlarla yer yer ardalanan şistlerden oluşmaktadır. Orta-kalın tabakalanmalı kireçtaşları metamorfizma sonucunda mermerleşmiştir. Bolkar mermerleri genellikle koyu gri, kirli beyaz renkli orta-kalın tabakalı olmakla beraber taze kırık yüzeyi de kirli beyaz, krem, gri ve kahverengimsi gri renklerde sağlam, keskin köşeli ve kırıklı ve dayanımlıdır. Dolomitler çoğunlukla koyu gri ve kalın tabakalanmalı olup, mermerleşen kireçtaşı tabakaları ile uyum göstermektedir. Aşırı deformasyon nedeni ile Bolkar mermerlerinde kıvrımlanma ve faylanmalar gelişmiştir. Çevikbaş [3] tarafindan üye mertebesinde ayırtlanan şistler, Uçar [6] tarafindan Bolkar mermerleri içerisinde incelenmiştir. Karıncadağ ve dolaylarında yüzeylenen şistler alacalı renklerde yeşil, yeşilimsi mavimsi gri renklerde olup, serüzit-mikaşist ve kuvars şistler yaygındır. Şistler genellikle çok ince yapraklanmalı, kırılma klivajlı ve tektonizma nedeniyle aşırı derecede ezilmiş olarak bulunmaktadır. Bolkar mermerlerinin tabanı çalışma alanı içerisinde gözlenmemekte, üzerine ise Alihoca ofiyoliti, Madenköy ofiyolitik melanj1, Ömerli formasyonu ve Kalkankaya formasyonu tarafından açısal uyumsuz olarak örtülmektedir. Karıcadağ'da ise Horoz granodiyoritinin kuvars porfir damarları tarafindan kesilmektedir. Demirtaşlı ve ark. [7]'nin belirlemiş oldukları fosil kapsamına göre Bolkar mermer ve şistlerine Permiyen yaşı verilmiştir.

Karmaşık içerisinde yer alan şistler genellikle muskovit-klorit ve kalkşist olup yer yer aktinolit tremolit şistler olarak gözlenmektedir [3]. Bu alandaki şistler açık-koyu yeşil tonlarında kıvrımlı, ezilmiş ve yapraklanmalıdır. Melanj içerisindeki sarı renkli kalkşistler genellikle düzgün tabakalı olup, yer yer mercekler şeklinde bulunmaktadır. Ecemiş fay kuşağının doğu kenarı boyunca geniş yayılımlar sunan Akdağ grubu içerisinde yer alan platform karbonat özelliğinde açık-gri orta-kalın tabakalı kireçtaşından oluşan birim ilk kez Yetiş [8] tarafından Demirkazık kireçtaşı olarak adlandırılmıştır. Birim inceleme alanı dışında Pozantı güneydoğusunda Akdağ ve Findıklı kuzeydoğusunda Çetinlikdağı dolaylarında yüzeylenmektedir. 
Ecemiş fay kuşağı boyunca kuzeydoğudan güneybatıya uzunlamasına bir şerit boyunca yerleşen ve karasal bir ortam özelliği gösteren birime ilk olarak Yetiş [8], Çukurbağ formasyonu ismini vermiştir. Ruhsat alanının yakın çevresinde bulunan Fındıklı Köyü ve dolayları ile Pozantı İlçe'sinin doğu ve güneyinde yaygın olarak yüzeylemektedir. Çakıt suyu ve diğer dere kenarlar1 boyunca yaygın olarak bulunan alüvyonlar, mermer, kireçtaşı, granit, bazik ve ultra bazik kayalar ile inceleme alanı dışındaki Kırkgeçit derede daha çok volkanik kayaç parçaları ile mikritik kireçtaşı, radyolarit ve kuvarslardan oluşmaktadır. İnceleme alanındaki akarsular genellikle düşük enerjili ve örgülü akarsu özelliğindedir. Bölgede Pozantı deresinin Ecemiş fay kuşağına ulaştığı Şekerpınarı dolaylarında bulunan dinlenme tesislerinde su ihtiyacinı karşılamak amacı ile açılan sondajlar sırasında 4050 m’lik alüvyon kesilmiştir [6].

Bölgenin önemli kısmını içine alan bölgeye ait jeoloji haritası Şekil 1'de verilmiştir.

\section{PARAJENEZ VE MÍNERALOJISİ}

Sülfürlü mineral içeren maden yataklarının ilerleyen safhalarda asit drenajı oluşturup oluşturmayacağını belirleyen testler için cevherleşmenin parajenezinde görülen özellikle sülfür içeren minerallerin mineralojisi ayrıntılı olarak incelenmiştir. Bu sebeple gerek önceki çalışmalardan ve gerekse 2013 yılında çalışma alanından alınan numunelerde elde edilen bilgiler değerlendirilmiştir.

Çevikbaş [3] Karıncadağ'daki cevherleşmeleri de içine alan "Niğde Havzası'nın Jeodinamik Evrimi ve Maden Yatakları Bakımından Önemi” başlıklı tezinde Karıncadağ kurşun-çinko-bakır cevherleşmelerini Bolkardağ Grubu cevherleşmeleri başlığında ayrıca ele alarak ayrıntılı olarak incelemiştir. Burda görülen cevherleşmelerin açıldığı galeri ve yarmaları inceleyerek cevherleşmenin primer sülfit ve bunların oksitlenmesiyle oluşan ikincil çinko cevherleşmesi olarak saptamıştır. Etkin bir karstlaşmadan da bahseden yazar mineralojik incelemesinde pirit, kalkopirit, sfalerit ve galeniti birincil sülfit mineralleri olarak ayırmıştır. Gang mineralleri olarak kuvars, kalsit-dolomit, serüzit, klorit ayırt etmiş ve karbonatlardan bir kısmının siderit-ankerit olarak psödoömorf şeklinde götite dönüştüğünü açıklamıştır. Yazar Karıncadağ cevherleşmeleri ile ilgili bir parajenez ve süksesyon tablosu düzenlemiştir (Çizelge 1).

Çizelge 1. Karıncadağ yatağının cevher mineralleri [3].

\begin{tabular}{|c|c|c|}
\hline $\begin{array}{c}\text { Birincil } \\
\text { Mineraller }\end{array}$ & $\begin{array}{c}\text { İkincil } \\
\text { Mineraller }\end{array}$ & $\begin{array}{c}\text { Gang } \\
\text { Mineralleri }\end{array}$ \\
\hline Sfalerit & Smitsonit & \multirow{4}{*}{$\begin{array}{c}\text { Kuvars } \\
\text { Karbonat } \\
\text { Serisit } \\
\text { Klorit }\end{array}$} \\
\hline Galenit & $\begin{array}{l}\text { Serüzit, } \\
\text { Anglezit }\end{array}$ & \\
\hline Pirit & Limonit & \\
\hline Kalkopirit & $\begin{array}{c}\text { Malakit } \\
\text { Azurit } \\
\text { Kalkosin } \\
\text { Limonit } \\
\text { Götit }\end{array}$ & \\
\hline
\end{tabular}

Bölgede maden yatakları konusunda ayrıntılı çalışma yapan Akyıldız [5] hem Akdağ'daki Çinkur sahasından ve hem de Karıncadağ cevherleşmelerinden alınan cevher örnekleri üzerinde bir dizi mineralojik ve kimyasal analizler yapmıştır. Aynı örnekler o yıllarda CRPG (Fransa)'de mikroprop analizleri de gerçekleştirilmiştir.

Yazar doktora tezinde birincil sülfür minerallerinden sfelaritin öteki minerallere göre daha yüksek sıcaklıkta geliştiğini ve yarıöz şekilli pirit ile galenitin kalsit gangı ile sfelariti ornatarak çatlakları boyunca yerleştiğini belirtmiş ve maden mikroskobu görüntüleriyle bu tespitini vurgulamıştır (Şekil 2 ve 3).

Akyıldız [5]'a göre en yaygın görünen primer minerallerden pirit öz, yarı̈̈z ve özşekilsiz olarak bazen de süngerimsi yapıda olmak üzere iki tip mikroskopik görünüm göstermekte olup, 
Sülfürlü Mineraller İçeren Maden Yataklarında Isşletme Sırasında ve Sonrasında Asit Kaya (Maden) Drenajlarının Oluşup Oluşmayacağına Yönelik Kestirimler: Akdă̆, Karıncadă̆ ve Bolkardă̆ Örneği, 1. Bölüm

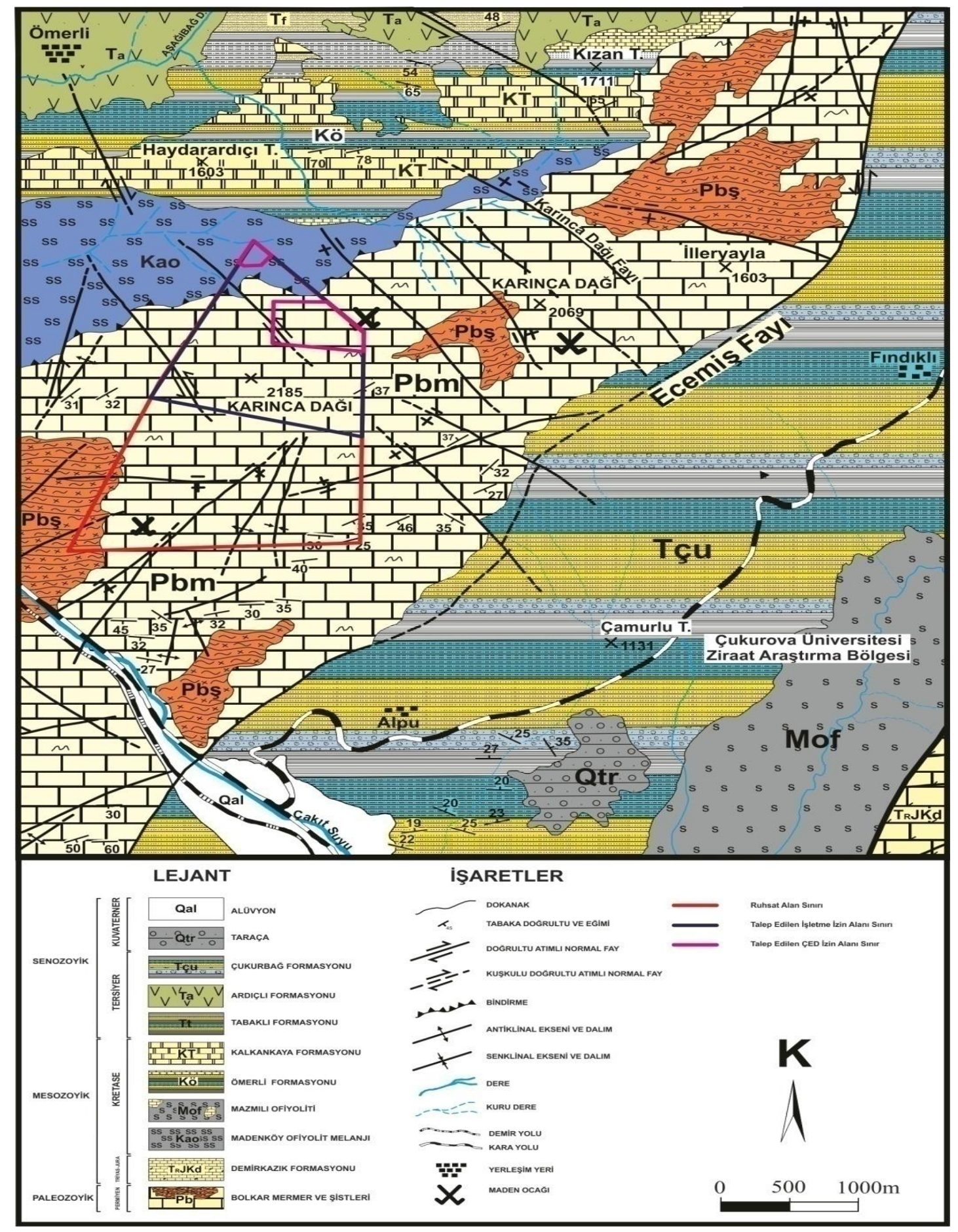

Şekil 1. Çalışma alanını da içine alan bölgenin jeoloji haritası [6] 


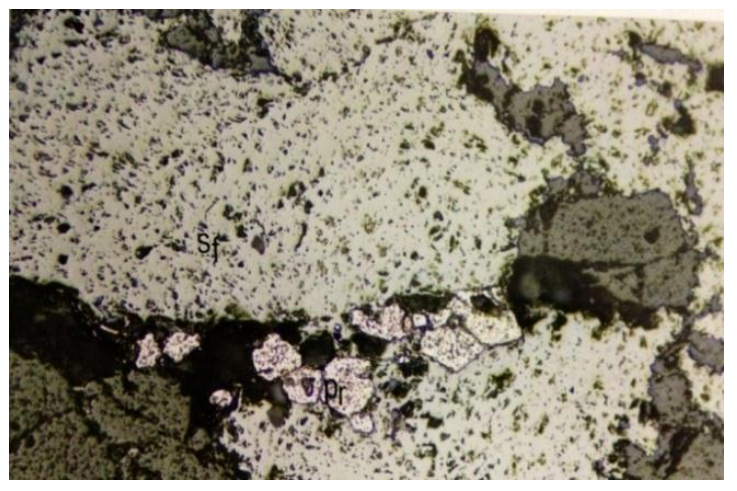

Şekil 2. Kahverengimsi-gri renkli özşekilsiz sfalerit (Sf), pirit tarafindan ornatılıış durumdadır.

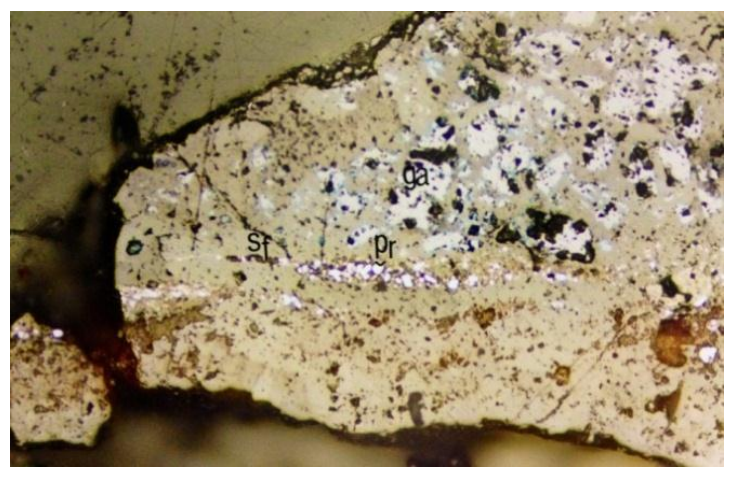

Şekil 3. Sfaleritin (Sf) boşluk ve kırıklarını dolduran galenit $(\mathrm{Ga})$ ve pirit $(\mathrm{Pr})$ kristalleri ile birlikte sfaleritin kenarları boyunca smitsonite dönüşmesi

birinci tipi galenit, sfalerit ve diğer cevher mineralleriyle öteki tiptekine göre daha büyük yarı̈̈z ve özşekilsiz piritler olduğunu belirtmiştir. Sfaleritlerle beraber olan galenitlerde elipsoidal ve yuvarlak taneler halinde fahlerz kapanımlarının varlığına dikkat çeken yazar, galenitin özellikle kenar ve kırık zonlarından itibaren serüzit ve anglezite dönüştüğünün açıkça görüldüğünü belirtmiştir.

Akdağ-Karıncadağ kompleks cevherleşmeleri için hem birincil (ana mineralizasyon) ve hem de ikincil cevher mineralleri (post mineralizasyon) için süksesyon tablosu hazırlamıştır. Birincil cevherleşmenin gerçekleştiği ana mineralizasyon evresinde ortamın sıcaklık basınç, pH, Eh gibi parametrelerle çözeltilerin bileşimlerinin değişmesi yeni minerallerin ortaya çıkmasına sebep olmaktadır. Yeni minerallerin ortaya çıkması evrenin bir yerinde kaybolması, minerallerin birbirini ornatması, kapanım veya ayrılımlar şeklinde kristallerin oluşması, yapı ve dokularındaki farklılıklarına göre yazar ana mineralizasyonda 3 evre saptamıştır (Çizelge 2). Kataklastik pirit, kuvars, kalkopirit ve seyrek olarak kalsit ilk evreye, sfalerit, öz ve yarı̈̈z şekilli pirit ve kalsit ikinci evrede kalsit ve galenit de son evrede oluşmuştur diyen yazar bunlarla birlikte çok az gözlenen fahlerz, neodijanit ile sfalerit, pirit ve seyrek olarak kuvarsin bu son evrede tekrarlandığını vurgulamıştır. Yazara göre 3 . evredeki sfaleritin içinde bazen kapanımlar şeklinde kalkopirit kapanımları da görülmüştür. Ana mineralizasyon evresinde oluşan cevher mineralleri gerek atmosferik şartların ve gerekse yüzey-yeraltı sularının etkisiyle ayrışarak oksitli ve karbonatl i ikincil minerallerden smitsonit, serüzit-anglezit, hidrozinkit, azurit-malakit ile limonite dönüşmüştür. Önceki yıllarda girilebilen galerilerin karstik mağaralara kadar ulaşması ikincil cevherlerin oluşumunda bir karstlaşma evresinin bölgede hüküm sürdüğünü işaret etmektedir. Benzer konumdaki Karıncadağ'ın güneyinde yer alan Akdağ Zn-Pb cevherleşmelerinde Roma devrinden kalan Çinkur galerilerinde de karstlaşma yaygındır.

Karıncadağ kompleks cevherleşme zonundan 2013 yllında alınan örnekler üzerinde de mineralojik incelemeler gerçekleştirilmiştir. Alınan numunelerin koordinat bilgileri ve saha tanımlamaları Çizelge 3'de verilmiştir. Tarafımızca alınan örneklerin mineralojik incelemeleri aşağıda ayrıntılı olarak verilmiştir.

\section{K-1: Oksitli Cevher}

Karstik erime boşlukları içeren ve diş görünüş itibariyle vişne çürüğü, açık kahverengi ve sarımtırak renkler içinde bir görünüşe sahip olan örnek içinde götit ve limonit hakim cevher mineralleridir. Birincil sülfür minerallerinden sfaleritin tamamına yakını ikincil smitsonite dönüşmüş durumdadır. Birincil sülfür zonundan 
Sülfürlü Mineraller İçeren Maden Yataklarında Isşletme Sırasında ve Sonrasında Asit Kaya (Maden) Drenajlarının Oluşup Oluşmayacağına Yönelik Kestirimler: Akdă̆, Karıncadă̆ ve Bolkardă̆ Örneği, 1. Bölüm

Çizelge 2. Akdağ-Karıncadağ kompleks cevherleşmelerinin mineral süksesyonu [5]

\begin{tabular}{|c|c|c|c|c|}
\hline \multirow{2}{*}{ Mineral } & \multicolumn{3}{|c|}{ Ana Mineralizasyon } & \multirow{2}{*}{$\begin{array}{c}\text { Post } \\
\text { Mineralizasyon }\end{array}$} \\
\hline & 1. Evre & 2. Evre & 3. Evre & \\
\hline Pirit & & & & \\
\hline Kalkopirit & & & & \\
\hline Sfalerit & & & & \\
\hline Galen & & & & \\
\hline Fahlerz & & & & \\
\hline Neodijanit & & & & \\
\hline Kuvars & - & & & \\
\hline Kalsit & & & & \\
\hline Smitsonit & & & & \\
\hline Anglezit & & & & \\
\hline Serüzit & & & & \\
\hline Malakit & & & & \\
\hline Azurit & & & & \\
\hline Limonit & & & & \\
\hline Hidrozinkit & & & & $-\square$ \\
\hline
\end{tabular}

Çizelge 3. Bölgeden 2013 yllında alınan numunelerin koordinat bilgileri ve saha adlanmaları

\begin{tabular}{|c|c|c|}
\hline $\begin{array}{c}\text { Numune } \\
\text { No }\end{array}$ & Koordinat & Saha Açılklaması \\
\hline K1 & 665761D, 4153040K & Sarımsi-açık kahverengi, oksitlenmiş \\
\hline K2 & 665789D, 4153005K & Oksitli zondan, K1 ile benzer özellikte ufalanmış durumda \\
\hline K3 & 665789D, 4153005K & Oksitli ve silisli zondan \\
\hline K4 & $665789 \mathrm{D}, 4153005 \mathrm{~K}$ & Oksitli, yüksek silisli zondan \\
\hline K5 & $665789 \mathrm{D}, 4153005 \mathrm{~K}$ & Oksitli, silisli ve kalsit kristalli zondan \\
\hline K6 & $665789 \mathrm{D}, 4153005 \mathrm{~K}$ & Gossan malzemeli yoğun okside zondan \\
\hline K7 & $665789 \mathrm{D}, 4153005 \mathrm{~K}$ & Mermer-Kalkşist, yankayaç \\
\hline K8 & 665789D, 4153005K & Mermer-Kalkşist, yankayaç \\
\hline K9 & 665765D, 4153033K & Silisli intrüsif \\
\hline K10 & $665765 \mathrm{D}, 4153033 \mathrm{~K}$ & Opak mineraller içeren mermer \\
\hline
\end{tabular}


kaldığı anlaşılan kuvars oldukça seyrektir (Şekil 4-5).

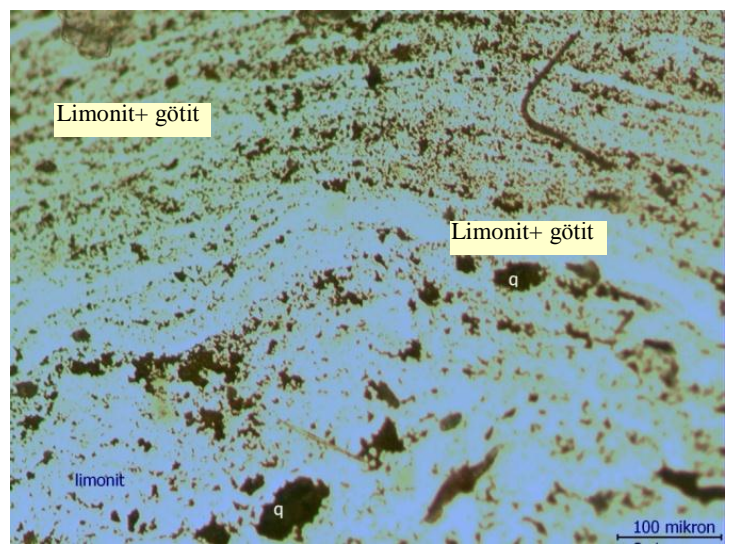

Şekil 4. Maden Mikroskobu, Yansıyan Işık, hakim mineral limonit+götit, daha çok karstik boşluklarda seyrek olarak gelişmektedir.

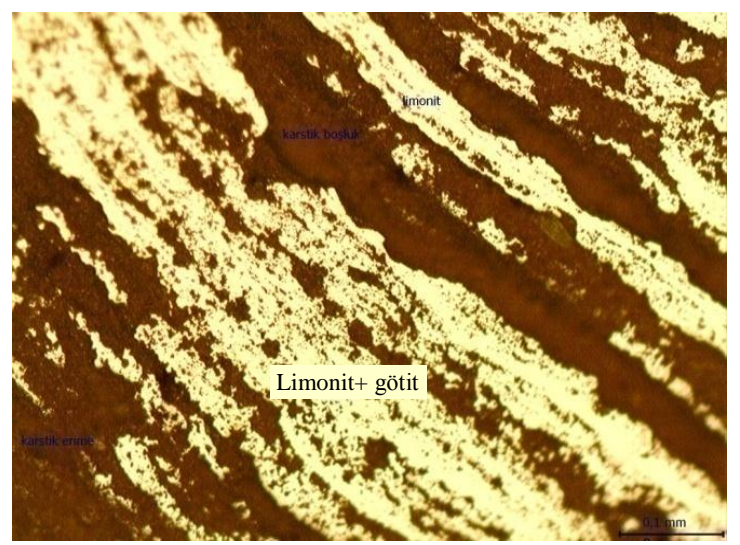

Şekil 5. Maden Mikroskobu, Y.I., alterasyon sonucu gelişen limonit ve götit, konsantrik ve yollu yapıların oluşumun uzunca bir süre devam ettiğini göstermektedir.

$\mathrm{Bu}$ numunenin ilksel konumunun birincil mineralleri bolluk sırasına göre pirit, sfalerit, galenit ve kalkopirit olmas1 muhtemeldir. Ancak süperjen alterasyonlar ve oksitlenmeler sonucunda piritin götit+limonite, sfaleritin ise smitsonite dönüştüğü ve karstik boşlularla diğer süreksizlik zonlarında dolaşan çözeltilerin bu çökelmelere sebep oldukları anlaşılmaktadır. Kimyasal formülü $\mathrm{HFeO}_{2}$ olan ve +adsorbe olarak büyük miktarda su içeren götit $\mathrm{Al}_{2} \mathrm{O}_{3}, \mathrm{CaO}$ ve $\mathrm{SiO}_{2}$ de içermektedir. Aynı örneğin XRF analizinde de bu durum açıkça görülmektedir. Hazırlanan parlak kesit örnekteki erime boşluklarının çok yaygın olması sebebiyle iyi kalitede parlatılamadığından pirit, sfalerit, galen ve kalkopirit gibi birincil mineralleri tayin etmek mümkün olmamıştır.

\section{K- 2: Toz Cevher Numunesi}

İleri derecede oksitlendiği ve rutubetini kaybedince kum haline geldiği için parlatılamamıştır. K1 örneğine oldukça benzer olup XRF analizinden götit+limonit, sfalerit+smitsonit varlığı anlaşılmıştır.

\section{K-3: Oksitli ve Silisli Cevherli Yankayac}

Numune silis zonundan alındığı için esas olarak kuvars, çok az karbonat ve biraz da demir oksitten oluşmuştur. Karstik erime boşlukları burada da görülmektedir. Parlak kesiti yaptırılan kayaç içinde hem mikro çatlaklar içinde ve hem izole olarak genellikle küçük boyutlu bol miktarda birincil sülfür mineralleri gözlenmiştir. Bunların en yaygını pirit olup genellikle öz ve yarı̈z şekillidir. Sfalerit ve galenite de seyrek olarak rastlanmıştır (Şekil 6-7).

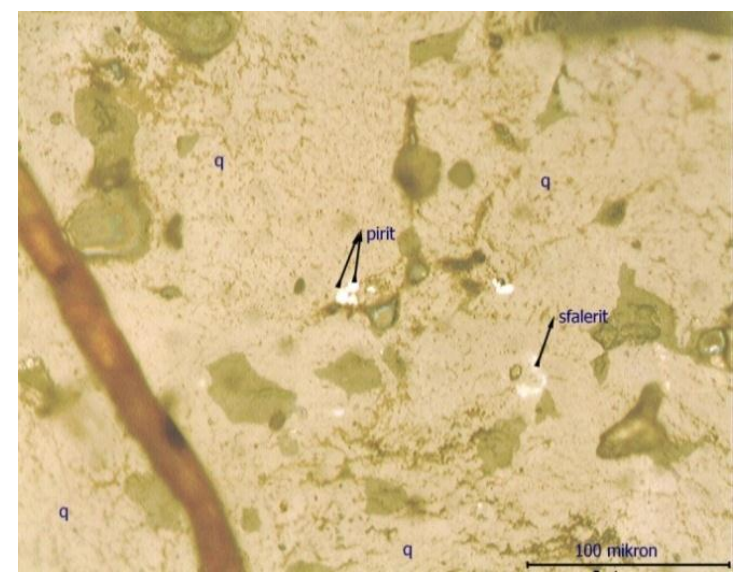

Şekil 6. Maden Mikroskobu, Y.I., Kuvars damarı içinde kırıklarda ve izole olarak görülen birincil sülfür minerallerinden en yaygını pirit 


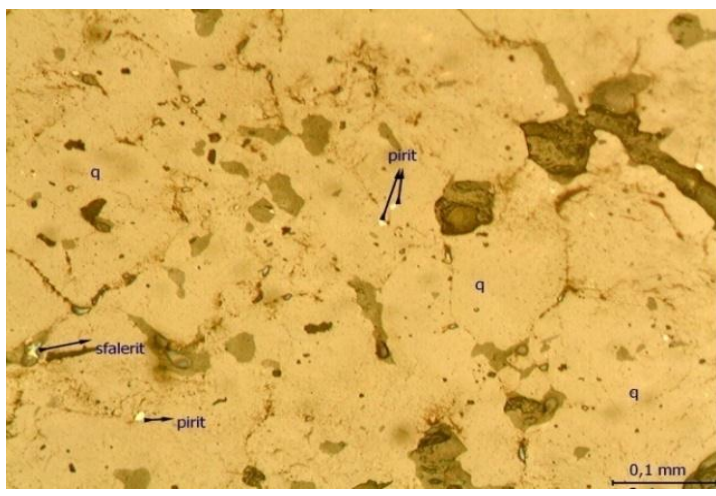

Sekil 7. Maden Mikroskobu, Y.I., kuvars içerikli damar içindeki pirit ve sfalerit.

K-4: Oksitlenmiş Silisli Zondan Alınan Numune Dış görünüşü itibariyle koyu ve açık kahverengi, yer yer yeşilimtırak yollu yapılı ve erime boşluklu bir yapıdadır. En hakim mineralin smitsonit (Şekil 8) olduğu XRF analiz sonuçlarından da anlaşılmaktadır. Götit ve limonit gibi ikincil minerallere smitsonitten daha az oranda rastlanmaktadır. Örnek içinde gelişigüzel dağılmış küçük boyutlu özşekilli pirit kristalleri görülmektedir (Şekil 9). $\mathrm{Bu}$ örneğin XRF analizinde büyük oranda $\mathrm{ZnO}(\% 68,81), \% \quad 0,1$ oranında $\mathrm{Co}_{3} \mathrm{O}_{4}, \% 10,8 \quad \mathrm{Nb}_{2} \mathrm{O}_{5}$ (Niobyum oksit), $\% 1,7 \quad \mathrm{PdO}$ (Palladium oksit)ve \%1,1 $\mathrm{Y}_{2} \mathrm{O}_{3}$ (Yitrium oksit) görülmektedir. XRD analizinde ise Sphaerocobaltit $\left(\mathrm{CoCO}_{3}\right)$ piki belirlenmiştir. Ayrıca ileri derecede oksitlenmeye uğramış örnek içinde hala birincil sülfür fazına ait pirit ve sfalerit seçilebilmektedir.

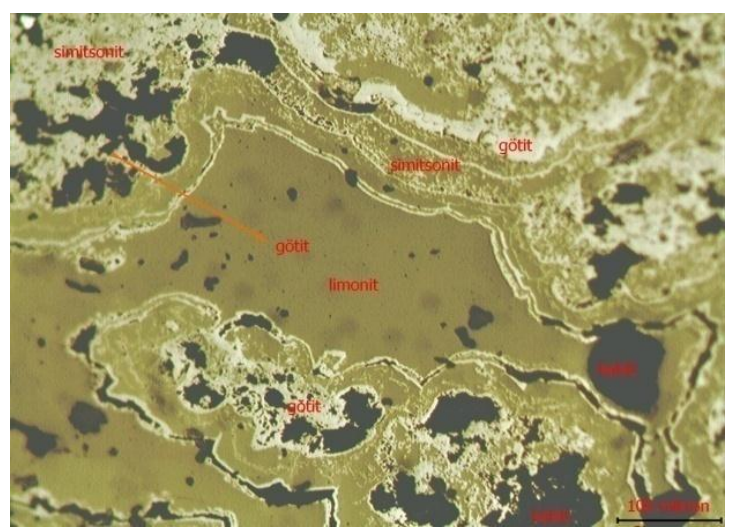

Şekil 8. Maden Mikroskobu, Y.I., konsantrik yollu yapılar sunan smitsonit, götit ve limonit

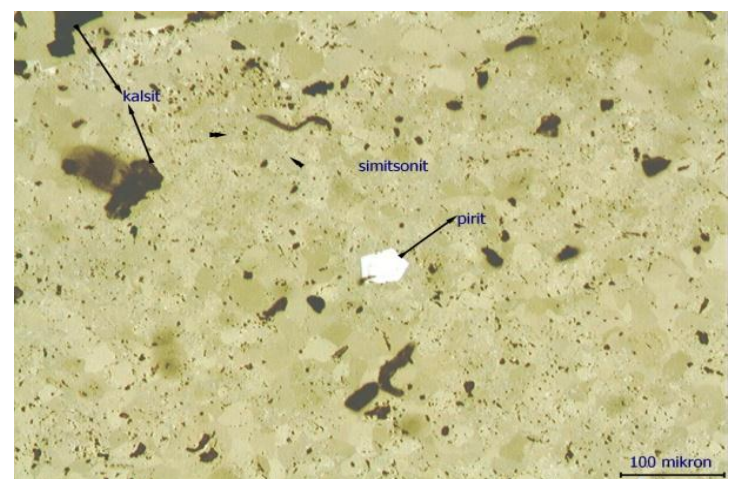

Şekil 9. Maden Mikroskobu, Y.I., aynı örnek içindeki yarıöz şekilli pirit

\section{K-5: Oksitli, Silisli ve Kalsit Kristalli Zondan Alınan Numune}

Kuvars damarlarının bariz olarak görüldüğü ve iri rekristalize kalsit kristallerinin çıplak gözle bile seçildiği numunede yankayacın mermer olduğu ve kuvars damarının bunun içine muhtemelen daha sonraki evrelerde girdiği anlaşılmaktadır. Gerek kuvars fazı ve gerekse mermerleşen karbonat içinde hem birincil sülfür mineralleri ve hem de onların alterasyon ürünleri görülmektedir. Sfalerit smitsonite, galenit anglezite, pirit de limonit ve götite dönüşmüş olmasına rağmen yine de numune içinde birincil sülfür mineralleri görülebilmektedir (Şekil 10-11).

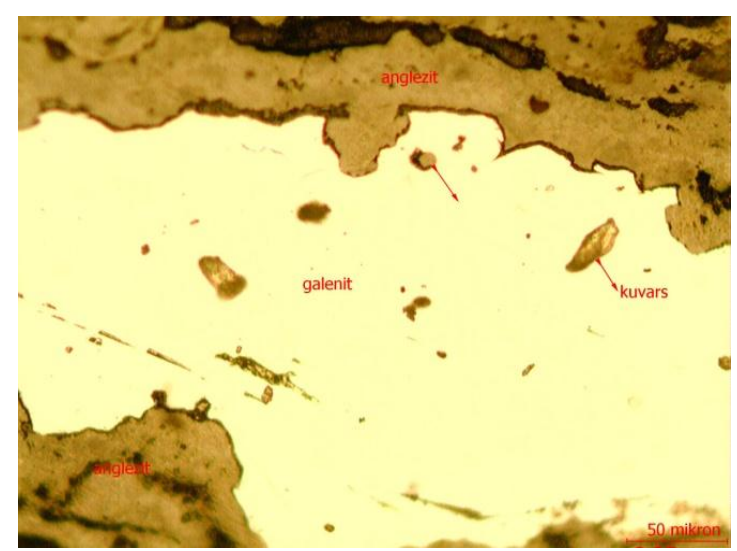

Şekil 10. Maden Mikroskobu, Y.I., cevher numunesi içinde primer sülfür minerallerinden galenitin kenar zonlarından itibaren anglezite ve serüzite dönüşmesi 


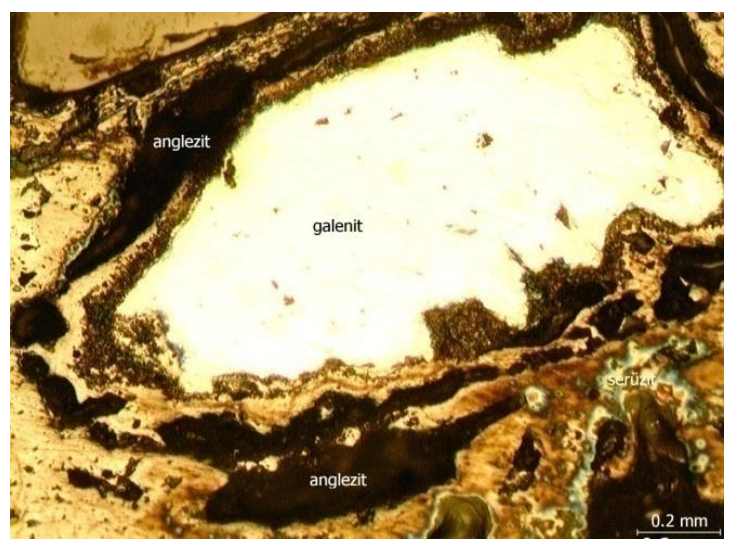

Şekil 11. Maden Mikroskobu, Y.I., primer galenitten dönüşen ikincil minerallere bir başka örnek

K-6: Gossan Malzemeli Yoğun Okside Zondan Alınan Örnek

Karstik erime boşlukları içeren ve dış görünüş itibariyle vişne çürüğü, koyu ve açık kahverengi yer yer sarımtırak renkler içinde bir görünüşe sahip olan örnek içinde götit ve limonit hakim cevher mineralleridir. Gang mineralleri kuvars ve kalsit oldukça yaygındır. Birincil sülfür minerallerinden pirit sıkça görülür (Şekil 12). Ayrıca muhtemelen arsenopirit, kalkopirit ve nabit altın gibi kompleks minerallere de seyrek olarak rastlanır (Şekil 13).

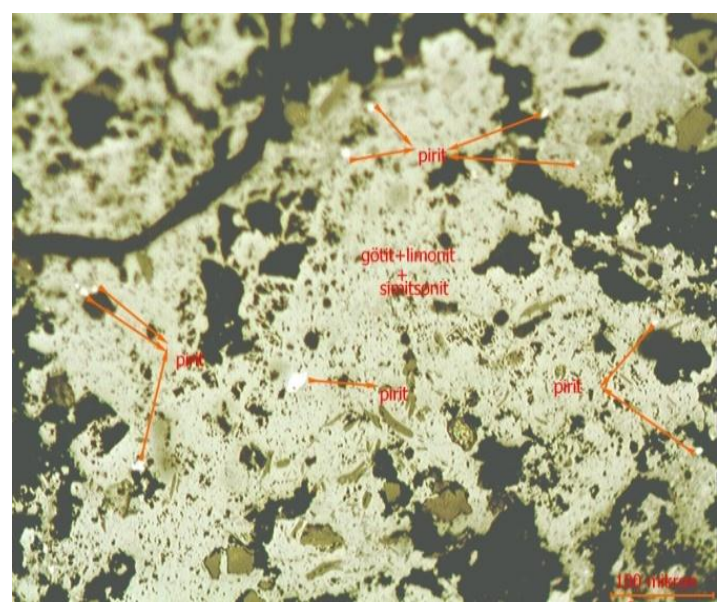

Şekil 12. Maden Mikroskobu,Y.I., götit+limonit+ smitsonit+pirit, gang olarak kalsit ve kuvars

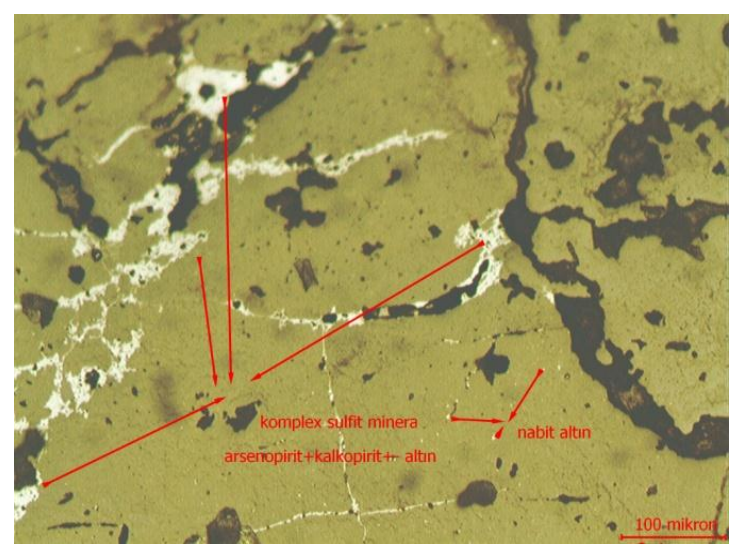

Şekil 13. Maden Mikroskobu, Y.I., götit+limonit içindeki kompleks sülfür mineralleri ve 5 mikrondan küçük nabit altın taneleri

Numunenin XRF analizindeki yüksek demir içeriği de neden koyu bir renge sahip olduğunu doğrular niteliktedir. Gözenekler ve erime boşluklarında gelişen ikincil karbonatların görülmesi de analiz sonuçlarından belli olmaktadır. Ayrıca XRD analizlerinde hem kuvars ve hem de kalsitin varlığ sabittir.

\section{K-7: Kayaç Numunesi}

Hazırlanan ince kesitin polarizan mikroskop altında incelenmesinde esas minerallerin rekristalize kalsit olduğu ve aralarında boşluk bırakmaksızın kenetlenerek oldukça masif bir yapı oluşturdukları görülmektedir. Mermerleşmenin tamamlandığı kayaç içinde gelişen gerek mikro çatlaklar ve gerekse çıplak gözle dahi seçilebilecek büyüklükteki kırıkların hem opak mineraller ve hem de kuvars kristalleriyle doldurulmuş olduğu gözlenmektedir (Şekil 14-15).

Numunenin genel durumu mermerleşmiş karbonat içindeki kırık ve çatlaklarda birincil sülfür fazına ait minerallerin geliştiği fakat sonraki evrelerde bunların önemli bir kısmının oksitlenerek ikincil faz minerallerine dönüştüğü anlaşılmaktadır.

XRF analiz sonuçlarından da bu durum belli olmaktadır. Gerek pirit, gerek sfalerit ve kalkopiritin düşük oranlarda olsa da kayaç içinde mevcut olduğu hatta kalayın bile iz olarak yer aldığı anlaşılmaktadır. Kırık ve çatlaklarda gelişen 
Sülfürlü Mineraller İçeren Maden Yataklarında Isşletme Sırasında ve Sonrasında Asit Kaya (Maden) Drenajlarının Oluşup Oluşmayacağına Yönelik Kestirimler: Akdă̆, Karıncadă̆ ve Bolkardă̆ Örneği, 1. Bölüm

cevherleşme içinde gang minerali olarak kuvarsın varlığı hem XRF ve hem de XRD analiz sonuçlarından açıkça görülür.

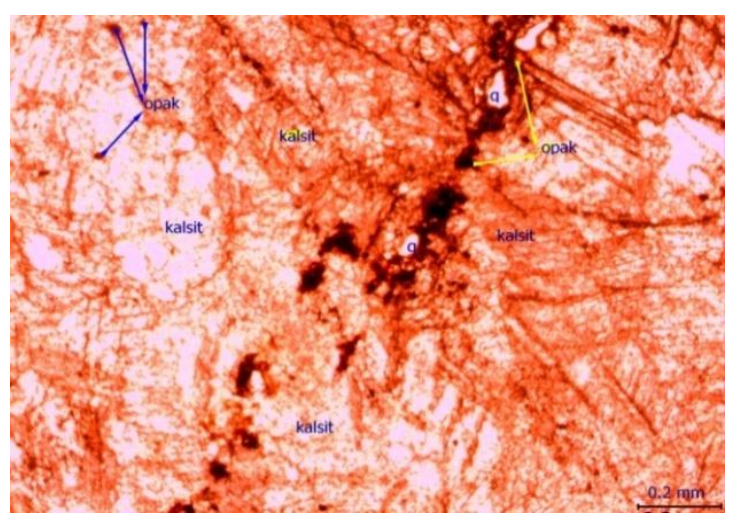

Şekil 14. Polarizan mikroskop, Tek Nikol, mermer içindeki kırık ve çatlaklarda ve izole olarak gelişen opak mineraller. Yan kayaç mermer olup kalsit kristalleri tamamen birbiriyle kenetlenmiş durumdadır.

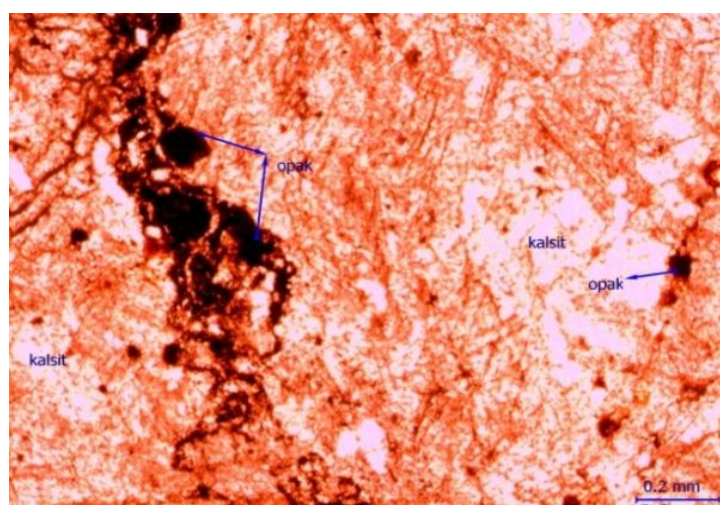

Şekil 15. Polarizan mikroskop, Tek Nikol, aynı örnekten başka bir görüntü. Opakların çoğu öz ve yarıöz șekilli pirit formunda gözlenmektedir.

\section{K- 8: Mermer-Kalkșist, Yankayac}

$\mathrm{Bu}$ örnekten parlak kesit yaptırılmış ve K7 örneğindeki durumların maden mikroskobu altında nasıl bir kompozisyon sundukları araştırılmıştır. $\mathrm{Bu}$ numunenin de esas olarak karbonat fazından oluştuğu ancak içindeki kırık ve öteki boșluklarda silisçe zengin cevher taşıyıcı çözeltilerin dolaşarak başta pirit, kalkopirit ve sfalerit gibi birincil sülfür minerallerinin oluşmasına sebebiyet verdikleri görülmektedir (Şekil 16-17).

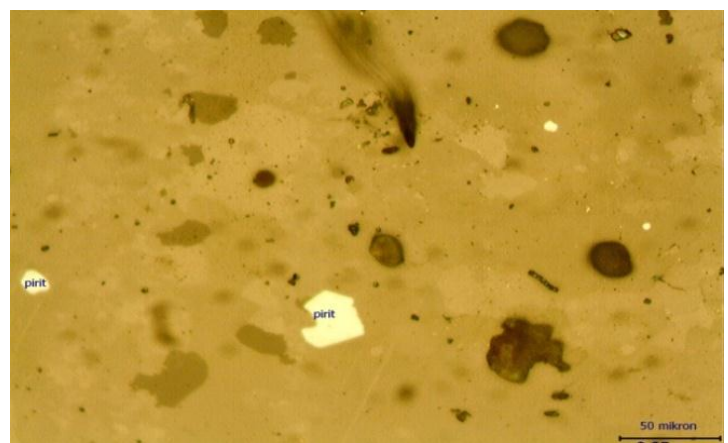

Şekil 16. Maden Mikroskobu, Y.I., mermerleşmiş karbonat fazı içindeki kırık ve erime boşlularında gelișen birincil sülfür fazından öz ve yarı̈z șekilli pirit. Yankayaç tamamen mermerden oluşmakta ve cevher minerallerine kuvarsın gang minerali olarak eşlik ettiği anlaşılmaktadır.

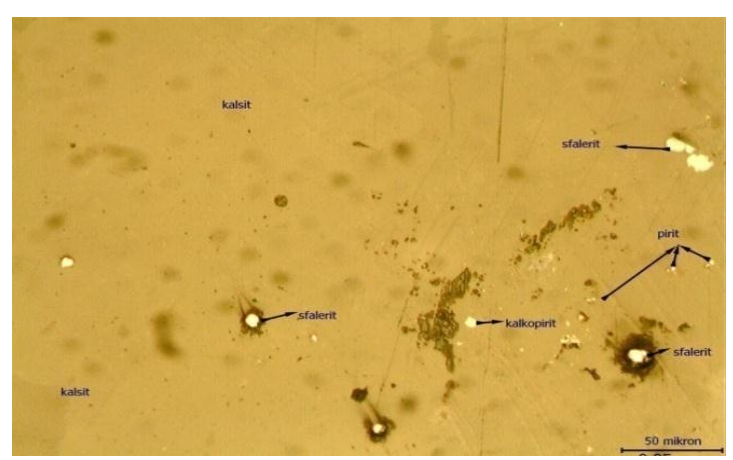

Şekil 17. Aynı örneğin bir başka kısmından alınan görüntü. Piritin yanı sıra gelișen kalkopirit ve sfalerit. Özellikle sfaleritin kenar zonlarından itibaren muhtemelen smitsonite dönüstüğü $5-10$ mikron mertebesinde bile seçilebilmektedir.

\section{K-9: Silisli İntrüsif Zondan Alınan Numune}

Silisifiye zondan alınan bu örnekte kuvars kristalleri çıplak gözle dahi görülebilmekte ve kayaçtaki mikro kırıkların sonradan okside olan 
primer minerallerin açığa çıkardığı opaklarla dolu olduğundan yer yer açık kahverengi rengiyle dikkat çekmektedir. $\mathrm{Bu}$ örnekten parlak kesit yaptırılarak maden mikroskobunda incelenmiş ve parlayabilen minerallerin oldukça küçük boyutlarda yankayaç içinde izole olarak dağıldıkları görülmüştür. Kırıklarda ince damarcıklar şeklinde gelişen sülfürlü minerallerin kesin tayinleri yapılamamıştır (Şekil 18). Ancak muhtemelen arsenopirit, kalkopirit ve nabit altın gibi kompleks minerallere de seyrek olarak rastlanır (Şekil 19).

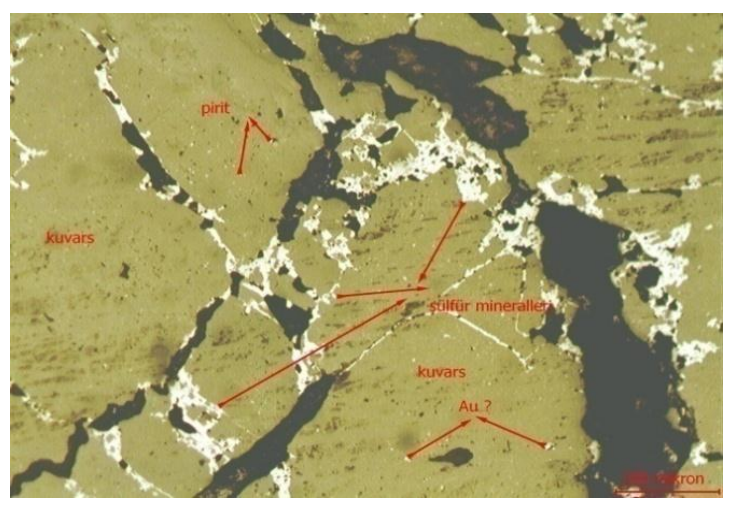

Şekil 18. Maden Mikroskobu, Y.I.,kuvars damarı içinde daha çok kırık ve çatlaklarda gelişen sülfür minerali. Ayrıca kuvars damarı içinde 10 mikron'u geçmeyen izole kapanımlar. Bunlar altın veya arsenopirit olabilir.

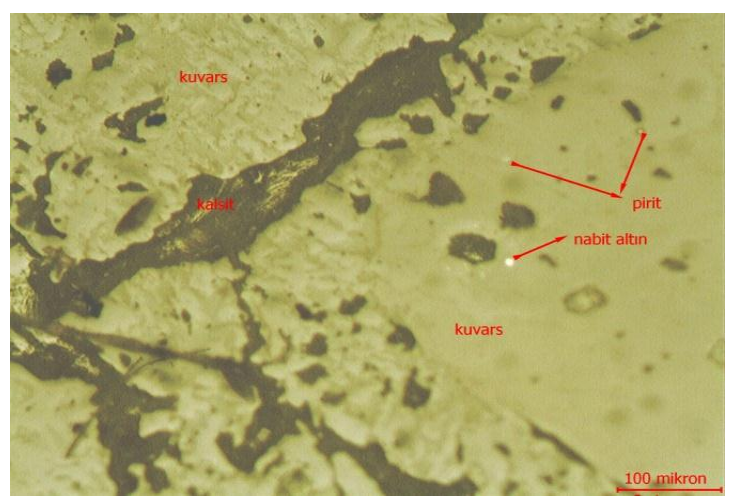

Şekil 19. Maden Mikroskobu, Y.I., aynı kesitten bir başka görüntü, kuvars kristalleri içinde küçük boyutlu pirit ve muhtemelen Au kapanımları
XRD analizlerinde \% 64'e yakın $\mathrm{SiO}_{2}$ görülen kayaçta $\mathrm{Cu}, \mathrm{Zn}, \mathrm{Pb}, \mathrm{As}, \mathrm{Rb}, \mathrm{Pd}, \mathrm{Cd}$, Pt ve $\mathrm{Au}$ gibi metallerin de iz olarak görülmesi bu kompleks minerallerin varlığına işarettir. Son yıllarda Türkiye'de özellikle Au tenörlerinin 1,5 g/ton'a inmiş olması önceki yıllarda düşük konsantrasyonlarda $\mathrm{Au}, \mathrm{Ag}$ ve $\mathrm{Sn}$ içeren geniş sahaların değerlendirilmesine firsat doğurmuştur.

\section{K-10: Opak Mineraller İceren Mermer}

Kayaç esas olarak mermerdir. Birbiriyle boşluk bırakmadan kenetlenen kalsit kristallerinin yanında seyrek olarak kuvars kristallerine de rastlanmaktadır. Kırıklarda ve erime boşluklarında gelişen opakların çoğunun öz ve yarı̈̈z şekilli pirit olduğu anlaşılmaktadır (Şekil 20). Bu kesitte sülfür minerallerinin oldukça seyrek görülmesi XRF ve XRD analizlerinden de görülmektedir. Aynı numunenin parlak kesitinde de benzer durumlar saptanmış olup çok küçük boyutlu piritin ve muhtemelen nabit altının ana kayaç içinde saçınımlar şeklinde yer aldığı görülmüştür (Şekil 21).

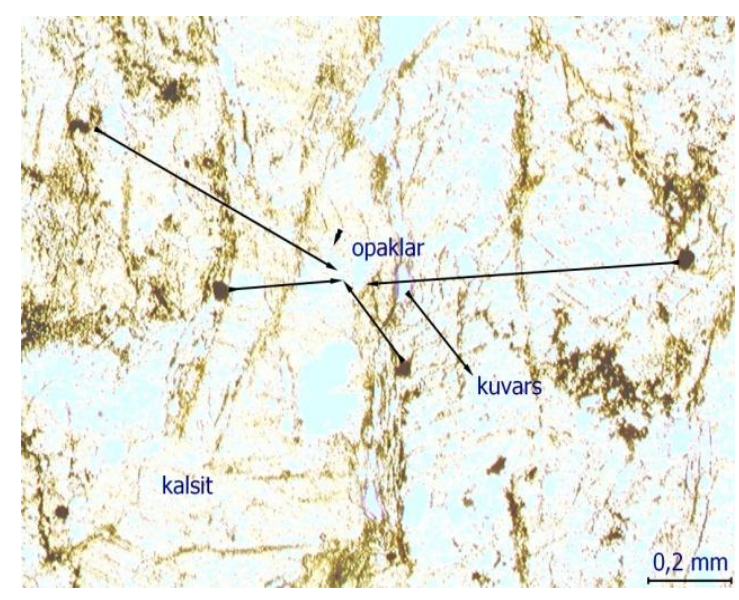

Şekil 20. Mikrofoto, Polarizan mikroskop, Tek Nikol, mermer içinde görülen opaklar ve seyrek rastlanan kuvars

Koordinatları Çizelge 3'de ayrıntılı olarak verilen 10 adet kayaç ve cevherli numunelerde gerçekleştirilen mineralojik incelemelerden arazi gözlemleriyle önceki yıllarda bu bölgede gerçekleştirilen çalışmalarda elde edilen bulgular ışığında Karıncadağ'ın tepe noktasının yaklaşık 


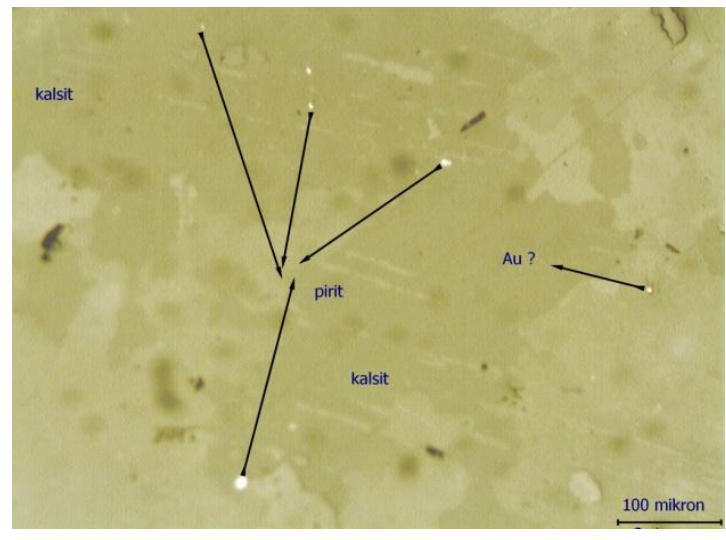

Şekil 21. Aynı numuneden yapılan parlak kesit. Maden Mikroskobu, Y.I. mermer içinde görülen saçınımlı opaklar

$600 \mathrm{~m}$ kuzey eteğindeki cevherleşmelerin Bolkardağ Mermerleri olarak adlandırılan [3-5] yankayaçları ince damarlar şeklinde kesen ve çoğunda silis içerikli bir yapı sundukları anlaşılmıştır. İşletme izin sahası içinde kalan ve çok önceki y1llardan kalma (bölgede Roma Dönemi olarak ifadeler kullanılmaktadır) ama Cumhuriyet döneminde birkaç defa yeniden açılan galeri ve yarmalarda yapilan aramalar olumlu sonuç vermemiştir.

Bu çalışmada alınan 10 adet örneğin mineralojik incelenmesinde de benzer sonuçlar bulunmuş olup pirit, kakalkopirit, sfalerit ve galenit birincil sülfür mineralleri olarak belirlenmiştir.

Gang mineralleri olarak kuvars ve karbonat (genellikle kalsit)'ın en yaygın olduğu bunlara özellikle karbonatlardan gelişen siderit-ankerit ve yalanc1 şekilli götit görülmüştür. $\mathrm{Bu}$ incelemelerden primer sfaleritin $\rightarrow$ smitsonit, galenitin $\rightarrow$ serüzit + anglezit, piritin $\rightarrow$ limonit, kalkopiritin $\rightarrow$ malakit, azurit, kalkosin, limonit ve götit gibi ikincil minerallere dönüştüğü bilinmektedir. Alınan 10 numune içinde en yaygın ikincil minerallerin smitsonit, anglezit+serüzit, limonit ve götitin tanımlanabildiği öteki ikincil minerallerin incelenen örnek sayısının az olması sebebiyle saptanamadığı anlaşılmıştır.
Alınan bu kayaç ve cevher örneklerinin kimyasal içeriklerinin belirlenmesi amacıyla da yarı kantitatif analiz yöntemi olan XRF ile analize tabi tutularak örneklerin durumu incelenmiştir. Daha sonra ayn1 toz numunelerden $(-0,106 \mathrm{~mm})$ XRD kristal faz diyagramları çekilerek en yaygın mineral fazları hakkında bilgi edinilmiş ve en son aşamada da bu toz numunelerinin büyütmeli binoküler mikroskop altında incelemeleri yapılarak metalik minerallerin görülüp görülmediğine bakılmıştır.

\section{XRF Analizleri}

Çalışma sahasından alınan 10 adet numunenin XRF yöntemiyle bulunan kimyasal içerikleri Çizelge 4'de verilmiştir.

\section{XRD Analizleri}

Aynı örnekler XRD analizi mineralojik analizi XRD (X-Ray Diffiraction) Rigaku Minflex II marka difraktometre ile $\mathrm{Cu} \mathrm{K} \alpha$ tüple, $2 \theta$ 10-90 arasında, $0,02^{\circ} / \mathrm{dk}$ ganyometre hızında yapılmıștır. Patternin kalitatif faz analizleri PDXL yazılımı ile yapılmıştır.

PDXL kalitatif analiz otomatik olarak minerallere ait pikleri ve profilleri her bir pik için genişlik, bütünleşmiş şiddet (pik yoğunluğu), pozisyon, yükseklik gibi pik bilgilerini doğrulayarak ayırmaktadır. Otomatik araştırma fonksiyonu veri tabanındaki doğrulanmış ayrıntılı pik bilgilerini kullanarak numunenin kristal fazını belirlemektedir. PDXL kalitatif analiz pik bilgilerini ve klasik profil bilgileri testlerini esas olarak çift karşılaştırma yaklaştırma kullanmaktadır. Seçilen numunelere ait faz diyagramları aşağıda verilmiştir (Şekil 22).

Gerek XRF analizleri yapılan ve gerekse XRD incelemeleri gerçekleştirilen 10 adet numuneye ait toz boyutundaki numunenin zum özelliği olan binoküler mikroskop altında ayrıntılı incelemeleri yapılarak opak mineral varlığı araştırılmıştır. Kimyasal ve mineralojik incelemelerde varlığ 1 belirlenen opak mineraller toz numuneler içinde de ayırtlanmıştır. 


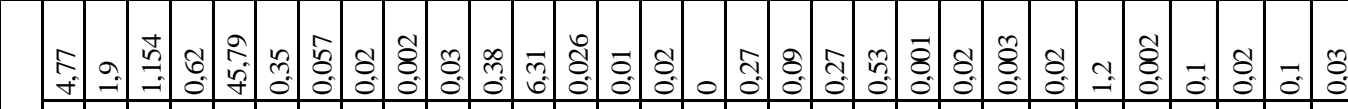

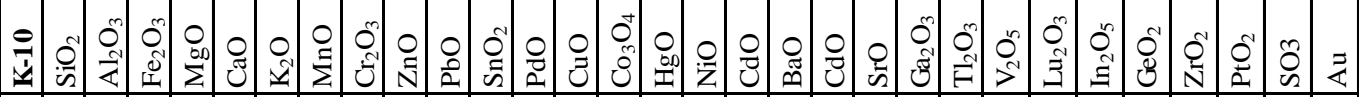

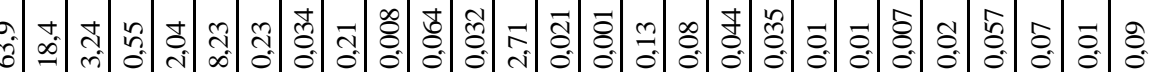

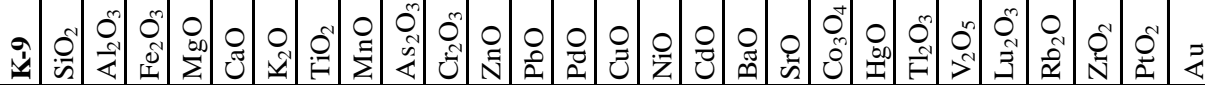

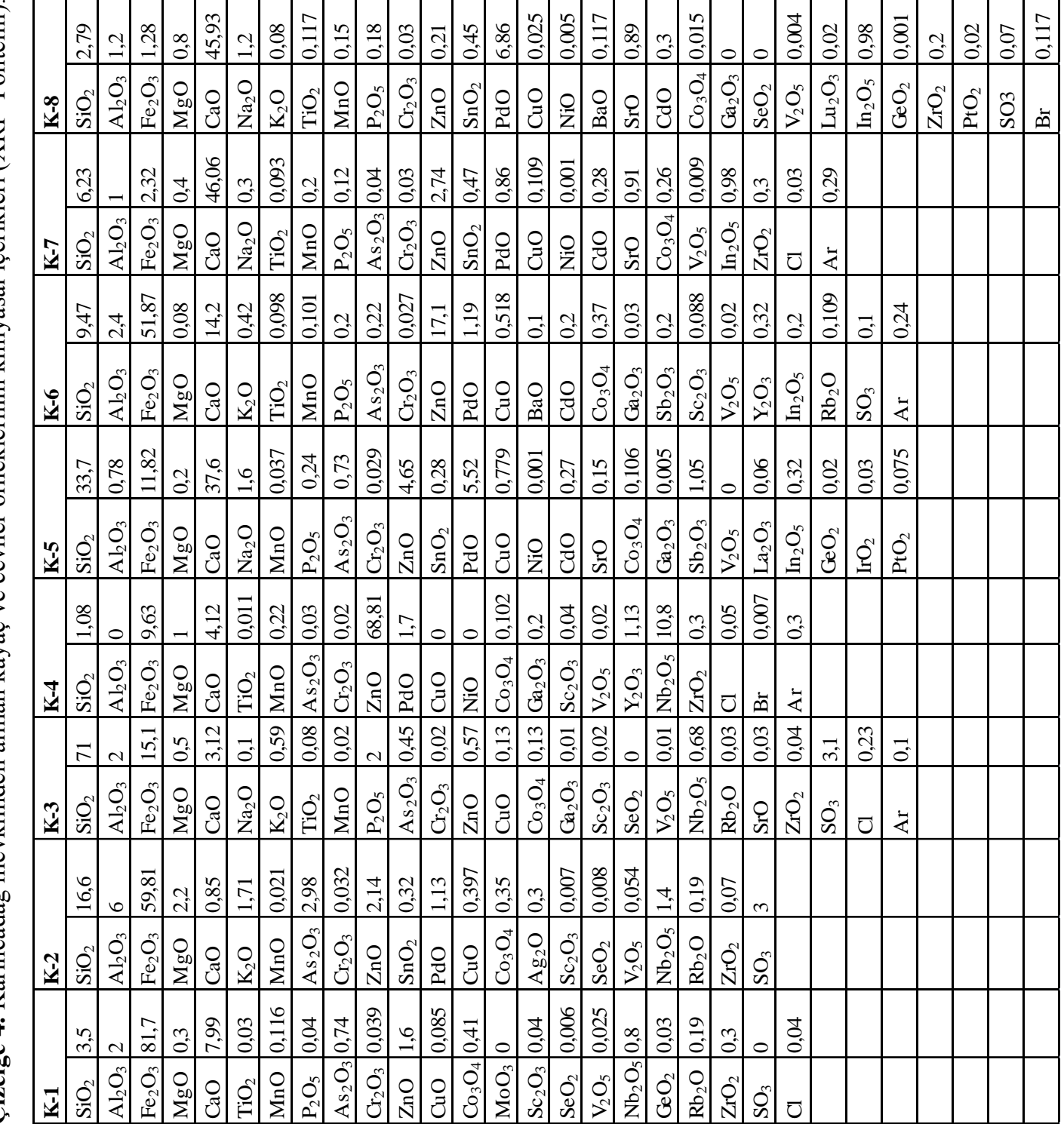



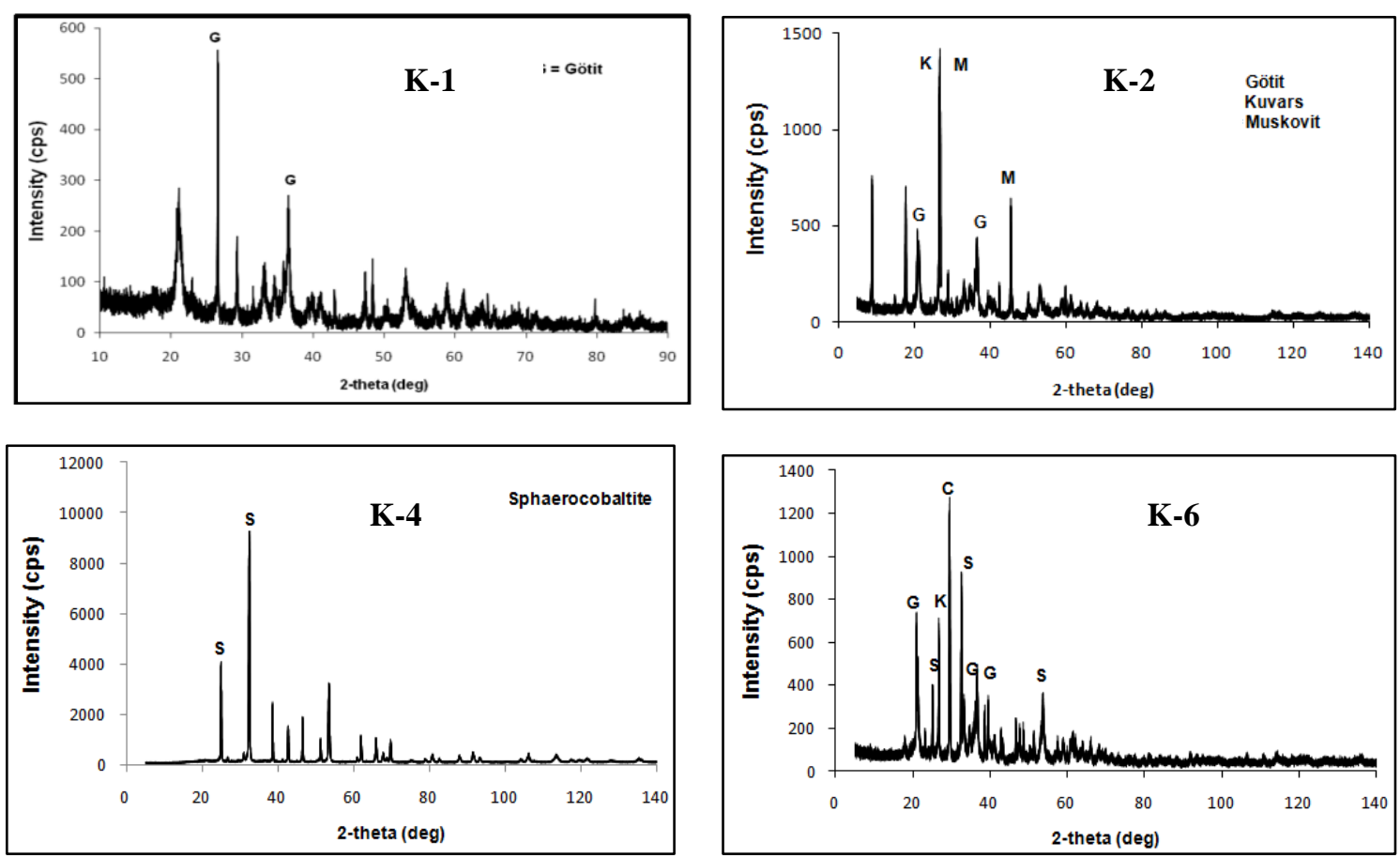

Şekil 22. Cevher zonundan alınan örneklerden K1, K2, K4 ve K6 numunelerine mineral faz diyagramları

\section{SONUÇLAR}

Adana İli, Pozantı İlçesi dahilinde Karıncadağ mevkiinde bulunan kompleks cevher (kurşun, çinko, bakır, altın ve gümüş gibi polimetalik cevherleşmeler) üzerinde 1950 'li yıllardan beri çok sayıda çalışma gerçekleştirilmiştir. Karıncadağ'ın güneyinde kalan Akdağ karbonatlı kayaçlar içinde $\mathrm{Pb}-\mathrm{Zn}-\mathrm{Cu}$ damarlarının içinde oldukça zengin bir primer sülfürlü parajenez bulunmaktadır. Bu birincil parajenezde esas olarak pirit, kalkopirit, sfalerit ve galenit gibi mineraller yaygın olarak görülmektedir. Birincil parajeneze tali olarak fahlerz, nabit $\mathrm{Au}$, Sn gibi değerli metaller de eşlik etmektedir. Gang minerali olarak ise en çok kuvars bazen de kalsit görülür. $\mathrm{Bu}$ parejenezde yer alan birincil cevher mineralleri gerek atmosferik şartların ve gerekse yüzey-yeraltı sularının etkisiyle ayrışarak oksitli ve karbonatlı ikincil minerallerden smitsonit, serüzit-anglezit, hidrozinkit, azurit-malakit ile limonite dönüşmüştür.
Alınan örneklerden hazırlanan parlak kesitlerin maden mikroskobunda incelemelerinde birincil parajeneze ait sülfürlü mineralleri çeper kısımlarından başlayarak dönüşüme uğrayıp piritin limonit ve götite, galenin anglezit ve serüzite, sfaleritin de smitsonit veya hidrozinkide dönüştüğü net olarak görülmüştür. Bolkardağ grubuna ait mermerleşen karbonatlar içinde de çok küçük prit kristallerini görülmesi, sonradan oluşan kırık ve çatlaklarında piritin oksitlenmesiyle oluşan opaklar oldukça yaygındır. Alınan örneklerin tozlarında çekilen XRD faz diyagramlarında XRF analizlerinde düşük konsantrasyonlarda görülen elementlerin oluşturduğu ikincil minerallerin varlığını göstermiştir. $\mathrm{Bu}$ birinci bölümde oldukça geniş bir alanda asırlardır varlığı bilinen polimetalik cevherleşmelerin mineralojik ve kimyasal incelemeleri yapılmış ve maden sahasında asit kaya/maden drenajının oluşup oluşmayacağı konusu sayfa sınırlaması sebebiyle 2. bölüme bırakılmıştır. 


\section{KAYNAKLAR}

1. Dilek, S., 2009., Maden-Madencilik, Altın ve Çevre, Altın Politikaları Sempozyumu, TMMOB Mad. Müh. Odası. Ankara.

2. Karadeniz, M., 2008. Sülfürlü Madenlerin Sorunu Asit Maden Drenajı ve Çözümü, MMO Yayını, 231 s, Ankara.

3. Çevikbaş, A., 1991. Ulukışla-Çamardı (Niğde) Tersiyer Havzasının Jeodinamik Evrimi ve Maden Yatakları Yönünden Önemi, Doktora Tezi, İ.Ü. Müh. Fak. Jeoloji Müh. Böl., 235 s. (Yayınlanmamış), İstanbul.

4. Çevikbaş, A., Öztunalı, Ö., 1991. UlukışlaÇamardı (Niğde) Havzasının Maden Yatakları, Jeoloji Mühendisliği, 39, 22-40, Ankara.

5. Akyıldız, M.,1999. Pozantı'nın (Adana) Doğu (Akdağ) ve Kuzeydoğusunda (Karıncadağ) Yüzeyleyen Kurşun-Çinko Yatakları, Ç. Ü. Fen Bilimleri, Enst., Doktora Tezi, 189 s.

6. Uçar, L., 1997. Gülek-Pozantı-Kamışlı (NW Adana) Dolayının Stratigrafik ve Sedimanter Petrografik İncelenmesi, Ç.Ü Fen. Bil. Ens. Doktora Tezi. $472 \mathrm{~s}$.

7. Demirtaşl1, E., Turhan, N., Bilgin, A. Z., 1986. Bolkar Dağları ile Ereğli-Ulukışla Havzasının Genel Jeolojisi. MTA Jeoloji etüdleri dairesi, 133 s., Ankara.

8. Yetiş, C, 1978. Çamardı (Niğde ili) Yakın ve Uzak Dolayının Jeoloji İncelemesi ve Ecemiş Yanlım Kuşağının Maden Boğazı-Kamıșlı Arasındaki Özellikleri: İ.Ü. Fen Fak., Doktora tezi, $151 \mathrm{~s}$, yayınlanmamış.

9. Anıl, M., Çetin, H., 2013. Adana ili, Pozantı İlçesi Karıncadağ Mevkiinde Bulunan ve Ruhsat Hukuku Koza Altın İşletmeleri A.Ş. de Bulunan IV. Grup Maden İşletme (Kompleks Cevher/Bakır, Kurşun, Çinko, Altın ve Gümüş) Sahasının Asit Kaya/Maden Drenajı Hususunda İnceleme Raporu, Ç.Ü. Mühendislik-Mimarlık Fakültesi, (Yayınlanmamış). 
